\title{
Different Perspectives of Creation and Knowledge Sharing in Virtual Environments
}

\author{
Rosane de F. A. Obregon"1, Tarcisio Vanzin², Vânia R. Ulbricht' ${ }^{2}$ \\ ${ }^{1}$ Science and Technology Centre, Bachelor Interdisciplinary Course in Science and Technology, \\ Federal University of Maranhão, San Luis, Brazil \\ ${ }^{2}$ Program Graduate Engineering and Knowledge Management, Federal University Federal University of Santa \\ Catarina, Florianopolis, Brazil \\ Email: antunesobregon@gmail.com, tvanzin@gmail.com, vulbricht@gmail.com
}

Received 2 March 2015; accepted 10 April 2015; published 15 April 2015

Copyright (C) 2015 by authors and Scientific Research Publishing Inc.

This work is licensed under the Creative Commons Attribution International License (CC BY). http://creativecommons.org/licenses/by/4.0/

(c) (;) Open Access

\begin{abstract}
In view of a society based on the synergy of individuals, groups, communities and social networks, this paper discusses the knowledge through the lenses of different theoretical perspectives. In this direction, this article aims to discuss some assumptions that structure the cognitive visions, social-interaction theory, and Situated Cognition, searching for aspects in common able to reduce boundaries and clarify the mechanisms that make the process of obtaining knowledge in individuals, groups and society. It is concluded that the conceptual convergence adopted by this study opens ways in order to clarify and expand the theoretical basis of the learning process and enable the strengthening of dialogue among individuals who interact in a context characterized by the use of new technologies.
\end{abstract}

\section{Keywords}

Cognitivism, Situated Cognition, Style, Social-Interaction, Symbolic Jungian Pedagogy, Online Learning

\section{Introduction}

The visualization of a society based on synergy of individuals, groups, communities and social networks over time generates inquires and theoretical prepositions in order to shape the knowledge acquisitive processes focused as well in individuals, groups and society. These theories offer tools of learning comprehension as emergent of a traditional educational system, the everyday familiarity, groups of social relationships, work and more recently the virtual environments provided by internet. However, the dynamics of changes caused by human, 
technological and scientific development among time, requires a review of pedagogic strategies, repaginated by Information and Communication Technologies (ICT) (Bazzo, 2015), which nowadays interfere also in the communication model between teacher/student, as well as in the pedagogic planning of the educational system (Obregon, 2011; Fialho, 2011; Bazzo, 2014).

The strategic position of society is focused on exploring the emerging technologies that resulted from the application of new knowledge. However, the present paradigms in society in this moment of transformation, are no longer enough to handle relations, needs and social challenges (Alonso, Manrique, \& Viñes, 2009). The learning culture that defines Society in Web converges the subject to the construction of a new educative model, characterized by individuals' diversity and plurality (Coll \& Monereo, 2008). It is relevant the contribution of writers such as Barney (1991), Boisot (1995), Spender (1996), Shapiro and Varian (1999), Teece (2000) and Barney and Hesterly (2006), considering that the learning processes, creation and sharing of knowledge became the most important source of sustainable competitive advantage in knowledge economy. On the other hand, Yoder (2008) and Mill (2006) warn for challenges, arguing that contemporaneity is poor of reflections concerning basic factors of educational process, such as: teaching, learning, sharing of knowledge management and technicalpedagogic mediation. According to Cordenonsi (2008) there is still a lot of work to do in order to break the positivist cycle, which can represent an inhibitor of new learning practices.

In order to restrict the focus analyzed by this article, it is important to mention that since the beginning of ICT use in education, people have thought about the most adequate pedagogic grounding to be adopted in virtual environment concepts. Traditionally, it has been searched the support of dominant paradigms of learning: the behaviorism, the social-interactionism and cognitivism. However, the persistent clash between these paradigms became the main epistemological conflict of pedagogic basement of online learning (Santos, 2002). In similar way, the works of Liu and Wang (2009) Chinese researchers that develop theories, technologies and products for e-learning, highlight the necessity of more consistent theories in order to better guiding the virtual systems. It is also possible to infer that current pedagogic proposals explore timidly the psychological context, considering that the emphasis is still on the cognoscenti subject—cognitivism—or on the subject as a result of social processes-social interactionism. It is also noticeable the predominance of perspectives concerning the subject in a fragmented and reductionist way, in detriment of the totality and subjective integration of being.

There are each time more evidences of a meaningful existing gap, demanding more investigation and analysis related to pedagogic perspectives and ways to establish educational relationships that respond to real needs of individuals and society (Bazzo, 2015). In this sense, there are opening spaces to discussions regarding specificities of psychological-pedagogic elements that allow the emergency of educative and innovative proposals which can amplify the conceptual basis of current approaches (Fialho, 2011).

Following this theoretical line, the contributions of Lave (1988) and Byington (2003) are quite adequate for questions concerning the motivation of this article: what is the relation between action, activity and knowledge? What generates the cognitive activity and motivates human production? What is the purpose of social-affective relationships in online learning process? How does the experiential dimension of interactions in virtual environments interfere in the educational process? Is it possible to establish connections between the different theoretical learning perspectives in order to support online proposals? It is exactly by dealing with these questions that reflexive contributions emerge from the clash between different theories, always followed by the interest of convergence and complementarity.

\section{Learning Processes: Interactionist Perspectives}

Following this analysis and focusing on the Brazilian scene, it is also important to consider the democratization process in the country by the 80s. This process pointed a significant change in the objectives and conceptions that used to guide the educational action until then. The Brazilian education boost changed the focus from "results" to "processes" of learning (Silva, 2006; Luckesi, 2002; Fialho, 2011). The new track adopted by Brazilian education (by focusing on "processes" instead of "results") marks the emergence of a new epistemic field so far inedited on the educational horizon. Studies and themes concerning Psychology and Neurology became relevant. Researches about mind functioning, the human development and sociability now have space in educational orientations. Some authors became more visible in this scene. It is the case of the cognitivist approach, brought by Piaget (1977), and the social-interactionist, having Vygotsky, Luria, Davidov and Leontiev as the most quoted references (Vanzin, 2005; Nuernberg, 2008). 


\subsection{Epistemic Emerging}

Piaget was read by many authors and overcame some reductionisms originally encompassed in constructivism denomination. The Piagetian review was guided by the discussion of human formation stages-the peculiarities of childhood, the teenage years, and the conditioners of developing processes. According to Fialho (2001), the study of mental representation or mental models, became the main theme of this approach. Under the cognitivist optic, learning means a dynamic mental process that is based on a sequence of experiences and provides a modification of behavior relatively stable concerning the way of thinking, feeling and acting (Obregon, Vanzin, \& Ulbricht, 2015). Following this line, learning represents information processing, turning the short-term memory to a long-term memory. When facing a problem, the person must get to a mental representation that allows him to elaborate a solution for the situation. This fact shows that solution comes from an internal interpretation, which came from the experience with the object (Fialho, 2001). Nevertheless, cognition corresponds to internal processes of information, which occurs through transformations of representations. Therefore, cognitivism considers the human being as a device of treatment and storage of information from the environment, however locked within himself (Vanzin, 2005).

Considering Byington's theory (2003), it is possible to infer that Piaget privileged the direct and pragmatic observation method of children intelligence development, with emphasis on thinking, the sensation and outgoing attitude. It is noticeable a learning process that is essentially objective and rational, mainly focused on external adaption, following a traditional positivist, causalist and materialist line from the XIX century.

\subsection{Unifying Tendency of Emotional and Cognitive Dimensions}

Maturana and Varela (1997) are two of the firsts who questioned the excessive weight the cognitive psychologists give to the concept of mental representation. The purpose was to explain the birth of human consciousness from social interactions and not only from biological structures. Knowledge is, necessarily, a product from a dynamic interaction with reality. Therefore, cognition is the effective action, where each action is a cognition proof, considering that knowing is making, in a sense of always existing an action connected to mental operations. Emotions are dynamic body dispositions which specify, every moment, the action domains. Therefore, according to these authors, there is not a human action without an emotion, which settles it and makes it possible as an action.

According to Oliveira (1992), it is possible to notice a unifying tendency of emotional and cognitive dimensions of psychological functioning of human beings. According to the author, this tendency lies on the necessity of recomposing the psychological being. In a similar way, filled by the reading of Jung and Morin, Camargo (2007: p. 19) affirms that "the objective knowledge is produced in the subjective sphere, having the subject present in all the known objects, trying to give a new sense and a new way of organizing life".

It was possible to identify in literature that several authors discuss the importance of emotion and an affectivity in learning processes; between them Piaget (1977), Vygotsky (1987), Maturana and Varela (1997) and Freire (1983). These authors are references for education researchers in studies of this fundamental aspect in educational processes, both in presential an online spaces. In addition, neuroscientific studies show that cognition and affectivity are equally relevant when it comes to learning. Therefore, learning requires motivation, responsible for stimulating desires, interests, attitudes and interactions of individuals (Coll \& Monereo, 2008).

Professor Kenski (2010) argues that the focus must be the "learning" process, since what really matters is that the students learn effectively. She adds that in order to reach a transformational learning, it cannot occur only in a rational sphere; it must be done completely. It is a behavior change and must involve not only reasoning, but specially feelings, emotion, intuition, and relate it with what is being learnt. According to Kenski (2010) this approach follows the pillars proposed by Delors (1996), to know: living, doing, being. The researcher proposes the inclusion of another pillar: "creating", which is a part of the intuitive process. Therefore, it is important to go further than just doing, and not simply repeating what everyone else has already done before. The sensation of this construction, this creation, brings the involvement, immersion, as a learning condition (Obregon, Vanzin, \& Ulbricht, 2015).

\subsection{Cultural and Historical Nature}

Differently from Piaget, Lev Vygotsky $(1987,1996)$ attaches the psychological human development to its cultural and historical nature, within the scientific vision of a developing society. Knowledge, according to this un- 
derstanding, is a result from the effective interaction with the objective world, where social builds the main development factor, adding elements to superior mental activities. The individual cognitive process becomes effective through an active evolution from living experiences in a real social conviviality, which provides structured values in a historical process. These cognitive gains occur conceptually, in a development proximal zone —DPZ (Cader-Nascimento, 2004; Moraes, Cardoso-Manso, \& Lima-Monteiro, 2009).

Vygotsky et al. (2003) consider that only in the beginning of life the biological factors are actually superior to historical-social factors from the environment where the child is inserted in. To dialectic Psychology, what truly defines is how each individual crosses these steps, what he builds on them and which activities were realized. To the author, there is not a universal sequence of cognitive stages, since historical-social conditions have several origins and, consequently, the interaction forms that allow mind and reasoning developments are different in each individual.

Among vygotskyans postulates, which concern the formation of knowledge, Luckesi (2002) affirms that spontaneous and informal learning occurs in multiple situations of everyday life. Following this line, Demo (2000: p. 129) sees knowledge as a "phenomenon typically dialectic, authentic unity of opposites, intrinsically contradictory", demanding that the individual leave the passive/receptive position and become dynamic and active. In this context, the human activity is mediated by social relations and language, since "the cognitive development is the conversion of social relations in mental functions (Moreira, 1999: p. 90). In order to amplify the vygotskyan speech, Moran, Marcos and Behrens (2001) add that "knowing” is relating, integrating, contextualizing, discovering; it means going further the surface, the predicable and externality.

In order to amplify the conceptual mark and making it more consistent, it is relevant the contribution of soviet Psychologist Aleksei Nikolaevich Leontiev (1903-1979), contemporaneous and collaborator of Vygotsky, known as one of the most important authors of Historical-Cultural or Social-Historical Psychology School, also called Vygotsky School. His speech is based on the principle that work assumes a fundamental role in the historical process of mental functions' evolution. To Leontiev (2003), the main focus is the external and internal human activity, as it is the basis of activity model. The mental processes are related to internal activities, which cannot be understood if isolated from external activities, since there is a mutual transformation between them (Vanzin, 2005).

Assuming Leontiev's approach as the research's anchor, Castro Neto, Gutierrez and Ulbricht (2006), highlight that the importance of individual's consciousness levels, the ways he develops it and the activity dynamic can influence on reasons/objectives to be reached. In this direction, Lúria (1990) affirms that the conscious human activity is, essentially, a dialectic, historical and-above all—objective movement. In addition, Gutiérrez (2002) says that the individual finds in his own social circle the external conditions that influence the development of his activities, procedures and semi optical mediators used. Therefore, in order to synthesize these theorizations concerning learning processes, it is possible to affirm that cognitive sciences approach mainly the mental representation. On the other hand, considering social-historical conceptions, the emphasis is on socialcultural aspects. It is now evidenced the conceptual polarization between these approaches. However, it is possible to infer that the activity theory of Leontiev (2003) allows a rereading of human learning, not only by a cognitivist optic of mental representations, but also incorporating it to interactions of social contexts.

\section{The Situated Cognition Theory (SCT)}

In order to realize the research presented in this article, it was adopted as a starting point the presuppose that any person has the capacity of learning and the structures and organizational systems many times do not allow the necessary engagement and sharing, causing psychological learning barriers. Considering this point, investigations in literature concerning Learning Theories point contributions of Lave (1988), who adopted an anthropological character while disserting about learning processes that happen in groups which develop activities and tasks in order to reach a common objective. It is about explaining nucleated learning no longer in Psychology, but in human doing and being, under the anthropological perspective and its consequences in a social environment.

\subsection{Social Theory: Learning and Social-Cultural Interactive Environment}

Lave (1988), Anthropologist with strong interest in social theory, defines cognition as a true social phenomenon and conceives the learning process as an elaboration of a social-cultural interactive environment. When looking 
closely to daily activity, Lave and Chaiklin (1993: p. 5) argue: "it is clear that learning is omnipresent in continuous activity, even though not recognized as such”. Her theoretical proposal, the Situated Cognition Theory (SCT) was elaborated along with Etienne Wenger and adopted anthropological presupposes and the analysis of social implications that resulted from groups of individuals that share specific objectives (Lave \& Wenger, 1991). In order to provide theoretical consistence, they used representations of Practice Communities as a scenery where human actors learn by executing actions and tasks that take them to a pre-established objective in a scene where objects, ways, concepts and values also have relevant roles (Obregon, Vanzin, \& Ulbricht, 2015). According to this conception, learning cannot be identified as a product of only one individual, but a result from relations in the group, with all the items in the scene and acting as a "Practice Community". This theorization exposes its own identity when confronted with behaviorism, cognitivism (specially the Piagetian construtivism) and social interactionism by valuing relationships between human agents and the situation elements (objects in the environment, including the available information). By that, the theory unites elements from cognition, perception and action within a social context, establishing a dialog between internal and external references, considering the interaction between the individual and the context where he is inserted in as an articulated link of all human actions (Suchman, 1987). Cognition, according to this theoretical line, corresponds concomitantly to an individual and social processing, where the emphasis lies on the "process", and the "how" occupies a featured position.

\subsection{Practice Communities}

In Practice Communities, the members share a common objective and engagement is a propellant element. There is the recognition of competencies from those who know less to those who know more. It means that learning occurs from the outside (those who know less) to the inside (those who know more), according to a mutual recognition. The elements that compose the Practice Community perceive and identify themselves, and consequently keep a network of cognitive interdependence and action. In this process, the community members share knowledge, values and results, what allows knowledge not to be restricted to one individual, but existing in a network that connects all group members. In summary, SCT proposed by Lave (1988) and developed by several authors such as Brown, Collins and Duguid (1989), Hutchins (2000), Suchman (1987), Clancey (1995) and others, preconizes that learning occurs in function of activity, context, culture and the social environment the individual is inserted in; that social interaction and collaboration are critical components for learning, by valuing the practice community. These authors also claim that this is the most adequate theory for processes of shared learning, including the web environment. With these characteristics, SCT establishes an important alignment with social-cultural aspects of social-historical interactionism from the soviet psychologist theoretical line involved within the learning process (Vanzin, 2005). Corroborating, Smith (2009) adds that much from Lave's work focuses on re-conception of learning, students and educational institutions, in terms of social practice.

\subsection{Situated Cognition}

The Situated Cognition incorporates several proposals that challenge the excessive value given by cognitivists psychologists to the representation concept. It is possible to identify the Situated Action from Suchman (1987), the Practice Communities from Lave and Wenger (1991) and the Distributed Cognition from Hutchins (1991). Apart from those, it can be added: the Incorporated Cognition (Varela, Thompson, \& Rosch, 1991) and Mind Ecology (Bateson, 1972). To Vanzin (2005: p. 26), this theory "[...] permeates several learning theories, by establishing with them a dialog of minimal conflicts in function of the social orientation that is adopted". Consequently, it opens space to revise current educational paradigms and allows the expansion of classical conception of human action against cognitivism and social interactionism. Considering more abstract presupposes of these theories, they might be more susceptible to mistakes when applied in practical terms. It means that they can be less efficient when dealing with questions that concern the way people organize their real working environments (Obregon, Vanzin, \& Ulbricht, 2015).

The analysis no longer concerns environment (behaviorism) or mental representation (cognitivism), but the interaction between both (Obregon, 2011). In addition, Venâncio and Nassif (2008: p. 97) show that language and emotion, information and knowledge can by analyzed considering a new focus, based on SCT: "the Situated Cognition allows the comprehension of information as a construction made by the individuals, from the realities 
lived by them”. The individuals are seen as historical being, social and contingents. To Tijero Neyra (2008: p. 5), in this approach "cognition is explained by the unification of corporeal, situational and cultural".

It is renounced the premise that there are universal principals which determinate the act of thinking, and it is now accepted the premise that actions and thoughts are developed in action, and in this direction SCT is lined up with the Leontiev's Activity Theory (2003). In this focus, it is valued the dynamic of people, the interactions between them and explicitness of knowledge. The bigger the sharing of ideas, the bigger the creative potential and, consequently, more knowledge production (Rogoff, Turkanis, \& Bartlett, 2001). The reflection is mainly focused on the "process", in exchanges between people, considering that plural sights sustain a collective construction. Then, motivation arises from the social environment and interacts concomitantly with intrapersonal factors from each individual. The creative process comes from the potential interaction between the individual and the social (Obregon, Vanzin, \& Ulbricht, 2008).

In order to synthesize Lave's works (1988) about situated cognition, Vanzin (2005) identifies it as a socialcultural cognitive system where knowledge is created by action and for the action. Therefore, the cognitive activities resultant from learning processes can only be explained when related to a context, being fundamentally situated. Adds that the SCT guidelines consider the teacher as a part of the process, acting in circumstances of necessity and not controlling or conducting the students' learning. The emphasis lies on the interaction between the individuals in a search for a common objective, as a way of production in a learning situation (Obregon, 2011). The interdependence matrix characterized by intense information and knowledge exchanges between individuals of a learning community favors initiatives of investigation, exploration and discussion that result in discoveries and learning. Therefore, the term "situated" has an intrinsic meaning that the individual's vision of cognitive activity is formed by the triad individual-task-context, from which the individuals interact socially in tasks of knowledge generation. In addition, Rézeau (2001) affirms that when the individual learns, it is a result of an intra and interpersonal social-interactive construction. However, this approach does not explain how relations emerge, neither clarifies how interactions are made in a deeper and psychological level, which results from the anthropological and not the psychological learning vision. It means that this theory identifies the way relations manifest, however it does not go deep on investigation of mental representations that structure and articulate the experiences from individuals and/or groups.

The literature review has also identified the contribution of Symbolic Jungian Pedagogy.

\section{Symbolic Jungian Pedagogy (SJP)}

The Symbolic Jungian Pedagogy (SJP) was presented by the psychiatrist and Professor Byington (2003). His approach takes as a model the method by which life naturally teaches, having the Symbolic Jungian Psychology as theoretical basis, also created by him; it describes the symbolic dimension that forms consciousness. The cultural matrix of SJP is based on works of Piaget, Neumann, Freud, Melanie Klein, Heidegger, Teilhard of Chardin and mainly Carl Jung, which the symbolic dimension, the main inspiration of Jung's work, led Byington to denominate his theory as Jungian (2003).

\subsection{Theory Approaches}

According to Byington (2003: p. 34), there are many approximations between his study and other approaches of modern pedagogy, since almost all of them identify and aim to overcome traditional limitations of conceiving learning, which means, the verbalism excess, dissociation between what is learnt and lived/experienced and, essentially, the separation between the subject and the object: "the dominantly rational pedagogy is limited and pedagogic redutivism based on knowledge transmission excludes essential experiences of being”. Adds that it is necessary to consider the psychic reality of the individual, constituted not only by what is rational and perceptible, but also by the emotional and intuitive dimension. Affirms that the reductionist model of comprehending participation and collective sharing possibilities is focused on sidedness, which excludes the systematic vision of all that composes the relations between the subject and the environment (Obregon, Vanzin, \& Ulbricht, 2015). The researcher highlights the slight relation of his approach with piagetians contributions, however identifies a difference of methodological nature: Piaget's perspective has a dominant influence of behavioral and cognitive psychology, focused on functions such as thinking, sensation and extroverted attitude. On the other hand, SJP is developed along with the four consciousness functions: thinking, sensation, feeling and intuition, and the two attitudes: extroversion and introversion. 


\subsection{Experiential Learning}

The SJP proposal is to rescue the emotional and pleasant experience of learning, in order to make it more efficient. It is based on the formation and development of personality and consequently including all life dimensions, such as: "Body, nature, society, idea, image, emotion, word, number and behavior" (Byington, 2003: p 15). The emphasis lies on living, evocating imagination in order to unite the objective and subjective within the symbolic dimension, to experience learning. The focus, which before was on abstraction and reasoning, is now on the development of personality and culture, turning the learning process into something ludic, emotional, stimulating and emergent of warm relations between all involved in the educative process. Defends the idea that "there is no teaching by using only thinking, sensation [...]" (Byington, 2008: p. 17), since it neglects the totality of being, the relation between the rational and emotional, leaving behind the psychic learning potential. Says that "this existential integration of intelligence that places every learning experience as something always relative, cause symbolic, having the possibility of being good or bad, creative or defensive, since all belongs to wisdom" (Byington, 2003: p. 276).

The main message of SJP is that "who experiences does not decorate", as it happens with who studies without experiencing, relating on rational levels and briefly forgetting. In his researches, Byington (2003) stated that in learning psychological theories the focus lies on rational learning, frequently on superficial levels, justified by considering the high percentage of forgetfulness of what was once "learnt". To the author, statistic researches are urgently necessary in order to point these fragilities in learning processes. Due to pedagogic tradition, the adopted procedure in education is the integral repetition of subjects by the teacher, and consequently inducing an education without deep experiences and propitiating the forgetfulness of contents. In addition, identifies another form of teaching: built from an exclusive rational form, without decorating, but searching truth by logic, which means that people ratiocinate and learn logically. However, another very different form of learning is when the person absorbs the rational emotionally, thru life experiences. The author says that "[...] the main factor that separates erudition from wisdom is the living and comprehension of its function on existential process" (Byington, 2003: p. 19).

To Furlanetto $(2010,1997)$ the individuals decode the physical world not only by formulating concepts based on reasoning, but attributing senses for what they experience and see. To attribute sense is something not only made on the consciousness plan, but includes unconscious aspects and requires not only the use of reason, but also another psychic functions such as intuition, emotion and imagination (Obregon, Vanzin, \& Ulbricht, 2015).

\subsection{Self Individual}

In this direction, the theoretical base defended by Byington (2003) is a pedagogic referential that aims to interrelate at the same time learning, utility, work and production sources with the subjects that are being taught, by relating them symbolically with life in general. To the author, the Jungian concept of Self individual "[...] approaches the dynamic interaction of all conscious and unconscious personality structures” (Byington, 2003: p. 21). While structuring SJP, the researcher amplifies the concept of Self to an educative context by proposing the Pedagogic Self, Group, Familiar, Cultural, Institutional, Planetary and Cosmic, among others. According to the author, the Group Self or Cultural includes all psychic subjective and object contents, applied in a group. The individual several experiences are connected to an Individual Self, operating from his roots, which means that the original and unique action has its own style, a personal characteristic (Furlanetto, 1997). However, the experienced contents are shared by those who participate of this articulation individual and social space (Obregon, 2011). Thru the Individual Self movement, other relations are established and these connect him to more amplified manifestations, realized by culture and retracting objective and subjective experiences, which happen in a certain place and time.

An important aspect pointed by Byington (2008) is that Self can be constituted/built/formed or not on its totality, depending on interaction, on established relations, always uniting the emotional, the rational, intuitive and perception. The bigger the interaction, dialogue, partnership, the bigger the strengthening and effectiveness of Group Self, considering that people feel more warmly welcomed in a learning environment. Therefore, it is noticeable a pedagogy based on relationships, which expresses the changes in several dimension of Self, basing knowledge in interdisciplinarity (Obregon, 2011). In this perspective, education is based on the psychic potential and not only on a part of it, presenting the difference between "Ego intelligence and Self intelligence" (Byington, 2003: p. 71). Therefore, in this perspective the relation the individual establishes with knowledge goes through 
the same way as other relations established with people and objects.

\section{Conceptual Convergence}

When talking about human lives, the interpretative and reflexive literature provided by theorizations of Lave (1988) and Byington (2003) points to language limitations exclusively objective. This language model tends to generalize, to search what is common, while human beings are unique and need to be perceived and recognized entirely. In this direction, the interdisciplinary nature that characterizes the conceptual convergence here presented, indicates the emergency of an innovative epistemological perspective (Obregon, Vanzin, \& Ulbricht, 2015).

The SJP preposition conjugates education chains, adding a personal perspective: initially, it is considered the genetic psychological approach of Piaget, but following a different line in order not to focus only on the rational and not being limited by evolutionary steps. Establishes an important conceptual adherence with Vygotsky, due to the archetypal concept of pedagogic transference, which is combined with the social-historical conception. In addition, by considering the symbol as the structure of individual and cultural Self, it allows to identify the presence of social Self dimension. This third observation converges to the principles of Situated Cognition Theory, which, by rejecting the dichotomy subject-object, highlights the situated context as the totalizer center of relations, in other words, the Group Self. The theoretical approximation that resulted in conceptual complementarity of SCT from the contribution of SJP was widely explicit in the research made by Obregon (Obregon, 2011) and is useful here as a guideline to the questions presented in this article. In other words, this theoretical approximation contributes to allow the following inferences:

1. The SCT, defended by Lave (1988) by rejecting the dichotomy of subject-object hegemony, follows the line of main presuppose of SJP, proposed by Byington (2003), that settles the relation between subject-object as the central dynamic in the learning process. There is an actual way of producing knowledge that can be done from the symbolic elaboration of social-cultural interactive environment;

2. The adoption of SCT is constituted in a common denominator to trivialize the theoretical alignment with psychological theories concerning learning, when highlighting relations that the individual establishes in a group situated context. This process is a result of learning with its respectives actors and scenes. In addition, SJP adds important constructs in order to explain how relations emerge and are established in a deeper level, which means in the psychic reality of individuals;

3. The relations established in Self level allow a circular learning movement through experiences lived by all elements in the situated context. In this perspective, the learning process occurs in Self level, which means, in the individual's totality of psychic reality, manifesting in the situated dimension of cognition. In a SJP language, the learning process it noticed through the ways established between the actors. It will result in collective learning practices that reflect in community relations, supported by common objectives, and by that way adhering to SCT. Therefore, learning is essentially existential, experiential, covering dimensions way ampler and crucial in the domain of human activities shared in a community;

4. SCT emphasizes that learning is not only about doing; it goes beyond, considering that it includes involvement, participation and interaction between the human or non-human elements in the situated context. By comparing this concept to SJP, this state of belonging, based on "relation", occurs in a deeper psychic level, in individual Self level and later Group/Pedagogic Self. The established intersection zones in the group potentiate the experiences, and consequently enrich the learning process and knowledge sharing. Thus, to perceive and comprehend the group movements contribute in a more effective way to amplify the individual and collective consciousness, and allow creation of a not very explored area in Education;

5. In the SJP conception, learning is an existential process that involves dimensions of psychic reality and cognition-the four structuring functions of consciousness: thinking, sensation, feeling and intuition. The main premise is based on dynamisms of polarities that coordinate human experiences, which means, the subjective and objective aspects when elaborating relations between the subject and the object.

The alignment here described allows the answer for the questions that originate this work: the theorizations allow to conclude that the relation the individual establishes with knowledge is the same as he establishes with other people, objects and/or information. It is stated the cognitive activity from the individual is characterized by the triad individual-task-context, and consequently affirming that relation exists within action, activity and knowledge. Therefore, the focus of social-affective relation stands out in learning processes. Equally, it is possi- 
ble to affirm that the experiences of interactions in virtual environments interfere in learning and define relations between individuals and between them with several communicational and informational systems (Obregon, Vanzin, \& Ulbricht, 2015).

In addition, the social aspect defended by Byington (2003), considering the SJP, claims that relations occur in a Self level, establishing relations with other social dimensions. In consequence, it is stated that the individual Self concept fits the Piagetian study object, which means, affirms the knowing subject. In addition, establishes a dialog with the vygotskyan social-historical subject when stating the social dimension of Self. Above all, strengthens the SCT arguments in what concerns sharing knowledge, objectives, values, spaces, tasks and results. The mutual recognition and perception of individual dimension as an element of the group system. The individual valuation (his approximation in the center of the group) lies on the result that the group, in that situation and with those objectives in mind, was capable of producing and identifying individual plots. In this direction SJP strengthens the arguments and proposes comprehension lines of actions concerning the group (community). In other words, adds that phenomena which permeate group experiences are grounded on the same modalities as relations that they can establish, which from those can be identified the "Selfs".

In this direction, to deal with interactionists learning perspectives is considering a wider area of possibilities for all individuals. The dialog established between different interactionist learning perspectives allow the advance of technological instrumentalization, considering the virtual environment filled with hypermedia potentiating resources of communication and exchanges. Therefore, the search for knowledge as the objective of learning process forms the main anchor of this study, allowed by the offered contributions from communication and information technologies, in order to achieve democratic and innovative proposals.

\section{Conclusion}

The cultural convergence of holistic movement that started this century, with a strong tendency of uniting basically all knowledge areas, represents a dynamic reaction movement of fragmentation and disciplining of knowledge, in order to rescue an interdisciplinary vision of several human activities. Following this line, it is possible to conclude that the conceptual convergence between Lave's (1988) and Byington's (2003) works allowed the immersion in an invisible zone, not very explored in education. The theoretical basis presented by this article will help understanding the relations between human and non-human elements present in educational contexts.

The substantiation of SCT is useful in order to understand the comprehension of online learning challenges, followed by the creation and knowledge sharing. Considering the social orientation that this approach adopts, it is established a dialog that allows the review and enlargement of classic conception of human action, focusing on cognitivism and social interactionism. The analysis basically concerns people's dynamic, the interaction and importance of exchanges between individuals and clarifies that plural points of view support and direct the collective construction. On the opposite of cognitive sciences which traditionally deal with human cognition as something established within the individual's mind-mental representations, SCT does not consider it as the only learning mechanisms.

Therefore, it is concluded that the theoretical convergence presented by this article indicates a new investigation horizon in order to understand learning processes and knowledge sharing in virtual environments, as well as uncovers a fertile scene for future researches and, by that, contributing for the science advance.

\section{References}

Alonso, F., Manrique, D., \& Viñes, J. M. (2009). A Moderate Constructivist e-Learning Instructional Model Evaluated on Computer Specialists. Computers and Education, 53, 57-65. www.eric.ed.gov

Barney, J. B. (1991). Firm Resources and Sustained Competitive Advantage. Journal of Management, 17, 99-120. http://dx.doi.org/10.1177/014920639101700108

Barney, J. B., \& Hesterly, W. S. (2006). Strategic Management and Competitive Advantage: Concepts and Cases. Pearson: Harlow.

Bateson, G. (1972). Steps to an Ecology of Mind. New York: Ballantine Books.

Bazzo, W. A. (2014). Science, Technology and Society: And the Context of Technological Education (Ciência, Tecnologia e Sociedade: e o contexto da educação tecnológica) (4 ed. rev.). Florianópolis: UFSC.

Bazzo, W. A. (2015). Technical and Human: Contemporary Issues (De técnico e de humano: questões contemporâneas). Florianópolis: UFSC. 
Boisot, M. H. (1995). Information Space: Framework for Learning in Organizations: Institutions and Culture. London and New York, NY: Routledge.

Brown, J. S., Collins, A., \& Duguid, P. (1989). Situated Cognition and the Culture of Learning. Institute for Inquiry. Educational Researcher, 18, 32-42. http://edr.sagepub.com/content/18/1/32.short

Byington, C. A. (2003). The Loving Construction of Knowledge: The Foundation and Purpose of Jungian Symbolic Pedagogy (A construção amorosa do saber: O fundamento e a finalidade da Pedagogia Simbólica Junguiana). São Paulo: Religare,.

Byington, C. A. (2008). Symbolic Jungian Psychology: The Voyage of Humanization of the Cosmos in Search of Enlightenment (Psicologia Simbólica Junguiana: a viagem de humanização do cosmos em busca da iluminação). São Paulo: Linear B.

Cader-Nascimento, F. A. A. (2004). The Implementation and Empirical Evaluation of Programs with Two Deafblind Children, Their Families and Their Teacher (A Implementação e avaliação empírica de programas com duas crianças surdocegas, suas famílias e a professora). Doctoral Thesis (Non-Published), Graduate Program in Special Education, São Carlos: Federal University of São Carlos.

Camargo, D. (2007). Jung and Morin: Critique of the Modern Subject and Education (Jung e Morin: Crítica do sujeito moderno e educação). São Paulo: Xamã.

Castro Neto, M., Gutierrez, A. J. C., \& Ulbricht, V. R. (2006). Distant Education without Distance (Educação a distância sem distância). Florianopolis: Pandion.

Clancey, W. J. (1995). A Tutorial on Situated Learning. In: J. Self (Ed.), Proceedings of the International Conference on Computer and Education (pp. 49-70). Charlottesville, VA: AACE. www.scopus.com

Coll, C., \& Monereo, C. (2008). Psychology of Virtual Education: Learning and Teaching with Information and Communications Technology. Madrid: Morata, S. L.

Cordenonsi, A. Z. (2008). Environments, Objects and Dialogicity: A Higher Education Strategy on Heuristics and Metaheuristics (Ambientes, Objetos e Dialogicidade: Uma estratégia de ensino superior em heurísticas e metaheurísticas). Doctorate Thesis, Porto Alegre: Federal University of Rio Grande do Sul, 228 p. https://www.lume.ufrgs.br/bitstream/handle/10183/14668/000666903.pdf?sequence=1

Delors, J. (Coordinator) (1996). The Four Pillars of Education (Os quatro pilares da educação). In: Education: The Treasure to be Discovered (Educação: Um tesouro a descobrir) (pp. 89-102). São Paulo: Cortezo.

Demo, P. (2000). Education and Knowledge. A Necessary Relationship, Insufficient and Controversial (Educação e Conhecimento. Relação necessária, insuficiente e controversa). Petrópolis: Vozes.

Fialho, F. (2001). Cognition Sciences (Ciências da Cognição). Florianópolis: Insular.

Fialho, F. (2011). A School for Tomorrow Wizards: An Interdisciplinary Being, Open to Dialogue (Uma escola para os magos de amanhã: Um ser interdisciplinar, aberto ao diálogo). Pinhais: Melo.

Freire, P. (1983). Pedagogy of the Oppressed (Pedagogia do oprimido). Rio de Janeiro: Paz e Terra.

Furlanetto, E. (1997). The Interdisciplinary Teacher Education from the Perspective of Symbolic Psychology (A formação interdisciplinar do professor sob a ótica da Psicologia Simbólica). Ph.D. Thesis, São Paulo: Pontifícia Universidade Católica.

Furlanetto, E. (2010). Interview by Rosane de F. A. Obregon. São Paulo/SP: The State University of São Paulo, September 25, 2010.

Gutiérrez, A. J. C. (2002). The Scientific Problem: The Formal Construction or the Delimitation in Real (O problema científico: Construção formal ou delimitação no real). Doctoral Thesis, Florianópolis: UFSC.

Hutchins, E. (1991). Organizing Work by Adaptation. Organizational Science, 2, 14-39.

Hutchins, E. (2000). Distributed Cognition. San Diego: IESBS University of California.

Kenski, V. M. (2010). Education without Distance: From Theory to Practice (Educação Sem Distância: Da Teoria à Prática) Proceedings of the 16th CIAED/ABED Round Table Conference, Foz do Iguaçú, September 2010. http://romerotori.blogspot.com.br/2010/09/educacao-sem-distancia-da-teoria.html

Lave, J. (1988). Cognition in Practice: Mind, Mathematics, and Culture in Everyday Life. Cambridge: Cambridge University Press. http://dx.doi.org/10.1017/CBO9780511609268

Lave, J., \& Chaiklin, S. (Eds.) (1993). Understanding Practice: Perspectives on Activity and Context. Cambridge: Cambridge University Press.

Lave, J., \& Wenger, E. (1991). Situated Learning: Legitimate Peripheral Participation. Cambridge: Cambridge University Press. http://dx.doi.org/10.1017/CBO9780511815355

Leontiev, A. (2003). The Development of the Psyche. São Paulo: Moraes.

Liu, Y., \& Wang, H. (2009). A Comparative Study on E-Learning Technologies and Products: From the East to the West. 
Systems Research and Behavioral Science, 26, 191-209. www.eric.ed.gov http://dx.doi.org/10.1002/sres.959

Luckesi, C. (2002). Evaluation of School Learning (Avaliação da aprendizagem escolar) (14th ed.). São Paulo: Cortez.

Luria, A. R. (1977). Cognitive Development: Its Cultural and Social Foundations. São Paulo: Ícone.

Maturana, H. R., \& Varela, F. (1997). Machines and Living Things. Autopoiesis, the Life Organization. Porto Alegre: Artes Médicas.

Mill, D. R. da S. (2006). Distance Education and the Work of Virtual Teaching: On Technology, Space, Social Relationships of Gender and Community in the Media Age. Doctoral Thesis, Belo Horizonte: Federal University of Minas Gerais, 310 p. http://www.bibliotecadigital.ufmg.br/dspace/handle/1843/HJPB-55Y9MT

Moraes, M., Cardoso-Manso, C., \& Lima-Monteiro, A. C. (2009). Affect and Being Affected: Body and Cognition among People with Visual Disabilities. Universitas Psychologica, 8, 785-792.

Moran, J. M., Marcos, T., \& Behrens M. A. (2001). New Technologies and Educational Mediation (3rd ed.). Campinas: Papirus.

Moreira, M. A. (1999). Meaningful Learning (Aprendizagem Significativa). Brasília: UnB.

Nuernberg, A. H. (2008). Vygotski’s Contributions for the Education of Visually Disabled People. Psicologia em Estudo, 13, 307-316. http://dx.doi.org/10.1590/S1413-73722008000200013

Obregon, R. de F. A. (2011). The Archetypal Pattern of Alterity and the Sharing Knowledge in Virtual Learning Inclusive Environment ( $O$ padrão arquetípico da alteridade e o compartilhamento de conhecimento em ambiente virtual de aprendizagem inclusivo). Doctoral Thesis, Florianópolis: Graduate Program in Engineering and Knowledge Management Federal University of Santa Catarina/UFSC, 210 p.

Obregon, R. de F. A., Vanzin, T., \& Ulbricht, V. R. (2008). AVA: Accessible Web Environment (Ambiente Web Acessível). Annals of the Brazilian Congress of Research and Development in Design, São Paulo: P \& D Design.

Obregon, R. de F. A., Vanzin, T., \& Ulbricht, V. R. (2015). AVA: Recommendations for Instructional Design in the Perspective of Alterity (AVA Inclusivo: Recomendações para Design Instrucional na Perspectiva da Alteridade). Volume 1, São Paulo: Pimenta Cultural, 234 p.

Oliveira, M. K. (1992). Vygotsky: Some Misconceptions in the Interpretation of His Thought. Cadernos de Pesquisa, 81, 6774.

Piaget, J. (1977). The Psychology of Intelligence. Rio de Janeiro: Zahar.

Rézeau, J. (2001). The Case of English Learning in Art History at the University. The Doctoral Thesis, Bordeaux: Université Victor Segalen Bordeaux 2.

Rogoff, B., Turkanis, C. G., \& Bartlett, L. (Eds.) (2001). Learning Together: Children and Adults in a School Community. New York: Oxford University Press.

Santos, A. I. dos (2002). Web-Based Adults’ Courses: Searching for the Right Pedagogy. Revista de Educação a Distância, ago. http://www.abed.org.br/publique/cgi/cgilua.exe/sys/start.htm/

Shapiro, C., \& Varian, H. R. (1999). Information Rules: A Strategic Guide to the Network Economy. Boston, MA: Harvard Business School Press.

Silva, M. (Org). (2006). Online Education: Theories, Practices, Laws, Corporate Training (Educação on-line: Teorias, práticas, legislação, formação corporativa). São Paulo: Loyola.

Smith, M. K. (2009). Communities of Practice. The Encyclopedia of Informal Education. www.infed.org.biblio/communities of pratice.htm

Spender, J. C. (1996). Making Knowledge the Basis of a Dynamic Theory of the Firm. Strategic Management Journal, 17, 45-62. http://dx.doi.org/10.1002/smj.4250171106

Suchman, L. (1987). Plans and Situated Actions. Cambridge: Cambridge University Press.

Teece, D. J. (2000). Managing Intellectual Capital: Organizational, Strategic, and Policy Dimensions. Oxford: Oxford University Press.

Tijero Neyra, T. E. (2008). The “Tautological Cognitivism” as an Epistemological Theory. Revista Virtual Interdisciplinaria El Árbol, 3. http://www.elarbol.cl/

Vanzin, T. (2005). TEHCO-Hypermedia Environment Model with Error Handling, Based on the Theory of Situated Cognition (TEHCO-Modelo de Ambientes Hipermídia com Tratamento de Erros, apoiado na Teoria da Cognição Situada). Doctoral Thesis, Florianópolis: Graduate Program in Production Engineering, Federal University of Santa Catarina / UFSC.

Varela, F., Thompson, E., \& Rosch, E. (1991). The Embodied Mind: Cognitive Science and Human Experience. Cambridge: MIT Press. 
Venâncio, L. S., \& Nassif, M. E. (2008). The Information-Seeking Behavior Grounded on the Situated Cognition Approach: An Empirical and Qualitative Study.

http://www.scielo.br/scielo.php?script=sci_arttext\&pid=S0100-19652008000100009\&lng=pt\&nrm=iso\&tlng=pt

Vygotsky, L., Luria, A. R., \& Leontiev, A. N. (2003). Language, Development and Learning (8th ed.). São Paulo: Ícone, 191 p.

Yoder, M. (2008). Constructivist Teaching: Virtual Worlds, Promising Technologies, Inspiring Examples. Proceedings of the 7th IASTED International Conference on Web-Based Education, Innsbruck, 17-19 March 2008, 293-298. 